\title{
Determination of Aprepitant in Human Plasma by Using LC-MS/MS with Electrospray Ionization
}

\section{Ravi Prakash PVDLS ${ }^{1}$, Sumadhuri $\mathrm{B}^{2}$ and Srikanth $\mathrm{M}^{3}$}

${ }^{1}$ Actimus Biosciences Private Limited, $3^{\text {rd }}$ and $4^{\text {th }}$ floor, Varun towers, Kasturbamarg, Siripuram, Visakhapatnam, Andhra Pradesh, India ${ }^{2}$ Department of Pharmaceutical Analysis and Quality Assurance, Bapatla College of Pharmacy, Bapatla, Andhra Pradesh, India ${ }^{3}$ Department of Pharmaceutical Sciences, A.U College of pharmaceutical Sciences, Andhra University, Andhra Pradesh, India

\begin{abstract}
A precise, sensitive and high throughput liquid chromatography-tandem mass spectrometry (LC-MS/MS) method for determination of Aprepitant (APT) in human plasma was developed and validated using Quetiapine (QTP) as internal standard. The analyte and internal standard were extracted from human plasma using liquid-liquid extraction. Chromatographic separation was performed on Discovery C18 $10 \mathrm{~cm} \times 4.6 \mathrm{~mm}, 5 \mu \mathrm{m}$ column with an isocratic mobile phase composed of $5 \mathrm{mM}$ Ammonium Acetate ( $\mathrm{pH} 4.00$ ):Acetonitrile (10:90), at a flow-rate of $0.9 \mathrm{ml} /$ min. The MS-MS detection was performed on a AB Sciex API 3200 tandem mass spectrometer operated in Multiple reaction monitoring (MRM) at positive mode at $\mathrm{m} / \mathrm{z} 535.10 / 277.10$ and $384.00 / 253.10$ for APT and QTP respectively. A linear dynamic range of 10.004-5001.952 $\mathrm{ng} / \mathrm{ml}$ for APT was evaluated with mean correlation coefficient $(r)$ of 0.9991. The precision of the assay (expressed as coefficient of variation, CV) was less than $15 \%$ at concentrations of LQC, MQC, HQC and was less than $20 \%$ for LLOQQC. Percent recoveries for APT at high, middle and low quality control samples was found to be $71.9 \%, 68.0 \%$, and $63.8 \%$ respectively and for internal standard $77.7 \%$. The analyte was found to be stable throughout five freeze-thawing cycles, bench top, wet extract, dry extract, auto sampler and interim stability studies. Therefore, the proposed method was found to be suitable for the routine quality control analysis of Aprepitant in human plasma in bioequivalence studies.
\end{abstract}

\section{Keywords: Aprepitant; Quetiapine; LC-MS/MS; Validation}

\section{Introduction}

Aprepitant (APT) is chemically $\quad(5-[[2(\mathrm{R})-[1(\mathrm{R})-(3,5-$ bistrifluoromethylphenyl)ethoxy]-3(S)-(4-fluorophenyl) morpholin4-yl]methyl]-2,4-dihydro-[1,2,4]triazol-3-one) and belongs to class of substance $\mathrm{P}$ antagonists (SPA). It acts as an anti-emetic by blocking the neurokinin $1\left(\mathrm{NK}_{1}\right)$ receptor. $\mathrm{NK}_{1}$ is a $\mathrm{G}$ protein-coupled receptor which is located in the central and peripheral nervous system having a dominant ligand known as substance P (SP). SP is found in high concentrations in the vomiting centre of brain and results in vomiting when activated. APT crosses blood-brain barrier and blocks SP by occupying $\mathrm{NK}_{1}$ receptors in brain neurons [1]. Thus, APT is used for the prevention of acute, delayed chemotherapy-induced and postoperative nausea and vomiting. It has little or no affinity towards $5-\mathrm{HT}_{3}$ receptors but it is shown to increase the activity of $5-\mathrm{HT}_{3}$ receptor antagonists such as ondansetron and the corticosteroid dexamethasone, which are also used to prevent nausea and vomiting caused by chemotherapy [2]. It has been recently demonstrated that substance $\mathrm{P}(\mathrm{SP})$ and neurokinin -1 (NK1) receptor antagonists induce cell proliferation and cell inhibition in human melanoma cells [3]. $\mathrm{NK}_{1}$ receptor antagonists might also reverse the impairment of NK cell function found in HIV infection via antagonism against SP, whose effects are mediated through $\mathrm{NK}_{1}$ receptor [4]. Currently, APT is also under evaluation as a new therapy in Neuro AIDS patients from the Integrated Preclinical and Clinical Program (IPCP) grant mechanism supported by the NIH at the Children's Hospital of Philadelphia and University of Pennsylvania [5].

Literature review reveals that very few analytical methods have been established for the estimation of APT. Estimation of impurities and Diastereomers in APT bulk drug substance [6], Characterization and Quantization of APT drug substance polymorphs by Attenuated Total Reflectance Fourier Transform Infrared Spectroscopy [7], stability of an extemporaneous oral liquid APT formulation [8], estimation of APT capsules by RP-HPLC [9], Stability-indicating HPLC method for quantitative analysis of APT $[3,10]$ were reported. Metabolic disposition of Aprepitant in rats and dogs was also reported [11]. Estimation of APT in rhesus macaque plasma, cerebral spinal fluid and in human plasma by LC-MS method was reported [12]. Other liquid chromatography and tandem mass spectroscopy methods for determination of APT in human plasma were also recently reported $[13,14]$. The present study describes development and validation of a simple, specific, rapid and sensitive liquid chromatography - tandem mass spectrometry (LC-MS/MS) method for the determination of Aprepitant in human plasma with a limit of quantification (LOQ) of $10.004 \mathrm{ng} / \mathrm{ml}$ during a $2.5 \mathrm{~min}$ run time using QTP as internal standard. The structures of Aprepitant and Quetiapine are displayed in figure 1.

\section{Materials and Methods}

\section{Reagents and chemicals}

Aprepitant (APT) (99.21\% purity), was obtained from Roorkee Research \& Analytical Labs Pvt.Ltd. and Quetiapine (QTP) (99.56\% purity) from Splendid Labs Pvt.Ltd., Pune, India. Methanol of HPLC grade obtained from Merck, Mumbai India. Acetonitrile and Tertiary Butyl Methyl Ether (TBME) of HPLC grade, Ammonium Acetate,

*Corresponding author: Ravi Prakash PVDLS, Actimus Biosciences Private Limited, $3^{\text {rd }}$ and $4^{\text {th }}$ floor, Varun towers, Kasturbamarg, Siripuram, Visakhapatnam, Andhra Pradesh, India, Tel: 91-9848490302; Fax: 91-891 6672111; E-mail: drpvdls@gmail.com

Received February 23, 2013; Accepted March 25, 2013; Published March 31 2013

Citation: Ravi Prakash PVDLS, Sumadhuri B, Srikanth M (2013) Determination of Aprepitant in Human Plasma by Using LC-MS/MS with Electrospray Ionization. J Bioequiv Availab 5: 110-116. doi:10.4172/jbb.1000143

Copyright: @ 2013 Ravi Prakash PVDLS, et al. This is an open-access article distributed under the terms of the Creative Commons Attribution License, which permits unrestricted use, distribution, and reproduction in any medium, provided the original author and source are credited. 
Citation: Ravi Prakash PVDLS, Sumadhuri B, Srikanth M (2013) Determination of Aprepitant in Human Plasma by Using LC-MS/MS with Electrospray Ionization. J Bioequiv Availab 5: 110-116. doi:10.4172/jbb.1000143

Formic acid and Ammonia of GR/AR grade were purchased from Fisher scientific Pvt. Ltd., Mumbai, India. High purity water was prepared through a Milli-Q water purification system.

\section{Instrumentation}

LC-MS/MS analysis was performed using API 3200 triple quadrupole instrument (Applied Biosystems SCIEX, Toronto, Canada) coupled with Shimadzu HPLC system (Shimadzu SIL HTC, USA) in multiple reaction monitoring (MRM) mode. Electron spray ionization in positive mode was used for ionization. Data processing was performed on Analyst software version 1.5.1. A high-speed desk centrifuge Sorvall Legend XTR Thermo Scientific was used to centrifuge the samples. Ultra microbalance SE2 of Sartorius and Semi Microbalance CPA225D of Sartorius was used for weighing the samples.

\section{MS/MS conditions}

The APT and QTP had Multiple reaction monitoring (MRM) at $\mathrm{m} / \mathrm{z}$ 535.10/277.10 and 384.00/253.10 respectively. The tuned MS/MS conditions of APT and QTP were represented in table 1. The mass spectrum of drug and IS are displayed in figures 2 and 3.

\section{Chromatographic conditions}

The separation of the compounds was made on Discovery C18 10 $\mathrm{cm} \times 4.6 \mathrm{~mm}, 5 \mu \mathrm{m}$ column. A mixture of $5 \mathrm{mM}$ Ammonium Acetate ( $\mathrm{pH}$ 4.00): Acetonitrile (10:90) was used as mobile phase and was filtered through $0.45 \mu$ membrane filters before use and degassed in an ultrasonic bath. All analysis was performed under isocratic condition at a flow rate of $0.9 \mathrm{ml} / \mathrm{min}$ at ambient temperature. The sample volume injected was $10 \mu \mathrm{l}$ with run time of $2.5 \mathrm{~min}$. Under the chromatographic

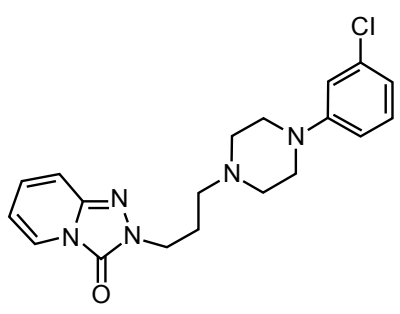

Trazodone

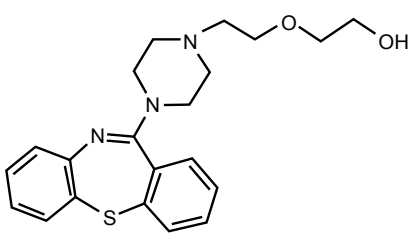

Quetiapine
Figure 1: Structures of Trazodone and Quetiapine.

\begin{tabular}{|c|c|c|}
\hline PARAMETER & APREPITANT & QUETIAPINE \\
\hline Declustering potential (DP) & 30 & 40 \\
\hline Entrance potential (EP) & 10 & 21.38 \\
\hline Collision cell entrance potential (CEP) & 26.37 & 55 \\
\hline Collision energy (CE) & 5 \\
\hline Collision cell exit potential (CXP) & 30 \\
\hline Curtain gas (CUR) & 6 \\
\hline Collision associated dissociation (CAD) & 4500 \\
\hline Ion spray voltage (ISV) & $475.00^{\circ} \mathrm{C}$ \\
\hline Heater temperature (TEM) & 40 \\
\hline Nebulizer gas (GS1) & \multicolumn{2}{|c|}{45} \\
\hline Heater gas (GS2) & \multicolumn{2}{|c|}{40} \\
\hline Table 1: Tuned MS/MS conditions of APT and QTP. \\
\hline
\end{tabular}

conditions described above, both APT and QTP were eluted with retention times of $1.55 \mathrm{~min}$ and $1.70 \mathrm{~min}$ (Figure 4).

\section{Preparation of standards and quality control samples}

The primary stock solutions of APT and QTP of $1000 \mu \mathrm{g} / \mathrm{ml}$ were prepared in methanol. The stock solution of internal standard was diluted to concentration of $400 \mathrm{ng} / \mathrm{ml}$ by using diluent $50 \% \mathrm{v} / \mathrm{v}$ methanol in water. The stock solution of APT was then serially diluted with $50 \%$ $\mathrm{v} / \mathrm{v}$ methanol in water to provide working standard solution of desired concentration. Standard stock solutions of APT were added to drug free human plasma to obtain calibration curve concentration levels of $10.004,20.008,500.195,1508.429,2432.950,3201.249,4001.562$ and $5001.952 \mathrm{ng} / \mathrm{ml}$. In a similar way, spiking of aqueous quality control dilutions was done in human plasma to prepare the quality control samples of concentrations $10.576 \mathrm{ng} / \mathrm{ml}$ (LLOQ QC), $25.181 \mathrm{ng} / \mathrm{ml}$ (LQC), $2098.448 \mathrm{ng} / \mathrm{ml}$ (MQC) and $3605.580 \mathrm{ng} / \mathrm{ml}$ (HQC). Primary stock solutions were kept at $2-8^{\circ} \mathrm{C}$ when not in use. All matrix based samples shall be stored in the deep freezer at $-70^{\circ} \mathrm{C} \pm 15^{\circ} \mathrm{C}$.

\section{Sample preparation method}

Required set of calibration curve standards and QC's were withdrawn from deep freezer and allowed them to thaw at room temperature. Thawed samples were vortexed to ensure complete mixing of contents. $50 \mu \mathrm{l}$ of internal standard solution $(400 \mathrm{ng} / \mathrm{ml})$ was taken into a RIA vial tube and $300 \mu \mathrm{l}$ of plasma sample was added to it and vortexed. $100 \mu \mathrm{l}$ of $2.0 \%$ (v/v) Ammonia solution was added to the above RIA vial and vortexed. To it $2.5 \mathrm{ml}$ of the Tertiary Butyl Methyl Ether (TBME) solution was added and vortexed at $2000 \mathrm{rpm}$ for about 10 minutes. The samples were centrifuged for $10 \mathrm{~min}$ at $4000 \mathrm{rpm}$ at $10^{\circ} \mathrm{C} .2 .0 \mathrm{ml}$ of supernatant layer from the centrifuged samples was taken into separate RIA vial. The samples were evaporated until dryness under the Nitrogen evaporator with $50^{\circ} \mathrm{C}$ of temperature. The samples were reconstituted with $300 \mu \mathrm{l}$ of mobile phase. Then the samples were transferred into auto injector and $10 \mu \mathrm{l}$ of sample was injected.

By using above materials and methods validation parameter were performed (i.e Auto sample carryover, Matrix effect, Precision and Accuracy, recovery and stability in matrix etc.)

\section{Results and Discussion}

\section{Method validation}

Validation runs were conducted according to the guidance of USFDA [15], on six consecutive days. Each validation run consisted of a minimum of one set of calibration standards and six sets of QC plasma samples at four concentrations of LLOQ QC, LQC, MQC and HQC.

\section{Auto sample carryover and Matrix effect with IS normalizing factor}

There was no carryover was observed by using optimised above LC-MS/MS and sample processing condition. Matrix ion suppression or enhancement effects on the MRM LC-MS/MS sensitivity were evaluated by the post extraction sicked samples. Different plasma lot Ob blank was extracted according to our sample extraction procedure. And then spiked Th analyte and internal standard into these matrixes. From the tach lot, three samples at two concentration (HQC and LQC) level were prepared. All these extracted and post extract spicked were analyzed by LC-MS/MS. It was observing matrix effect and IS normalizing factor for both analyte and internal standard accuracy \pm $15 \%$. The results were represented in tables $2 \mathrm{a}-2 \mathrm{~d}$. 

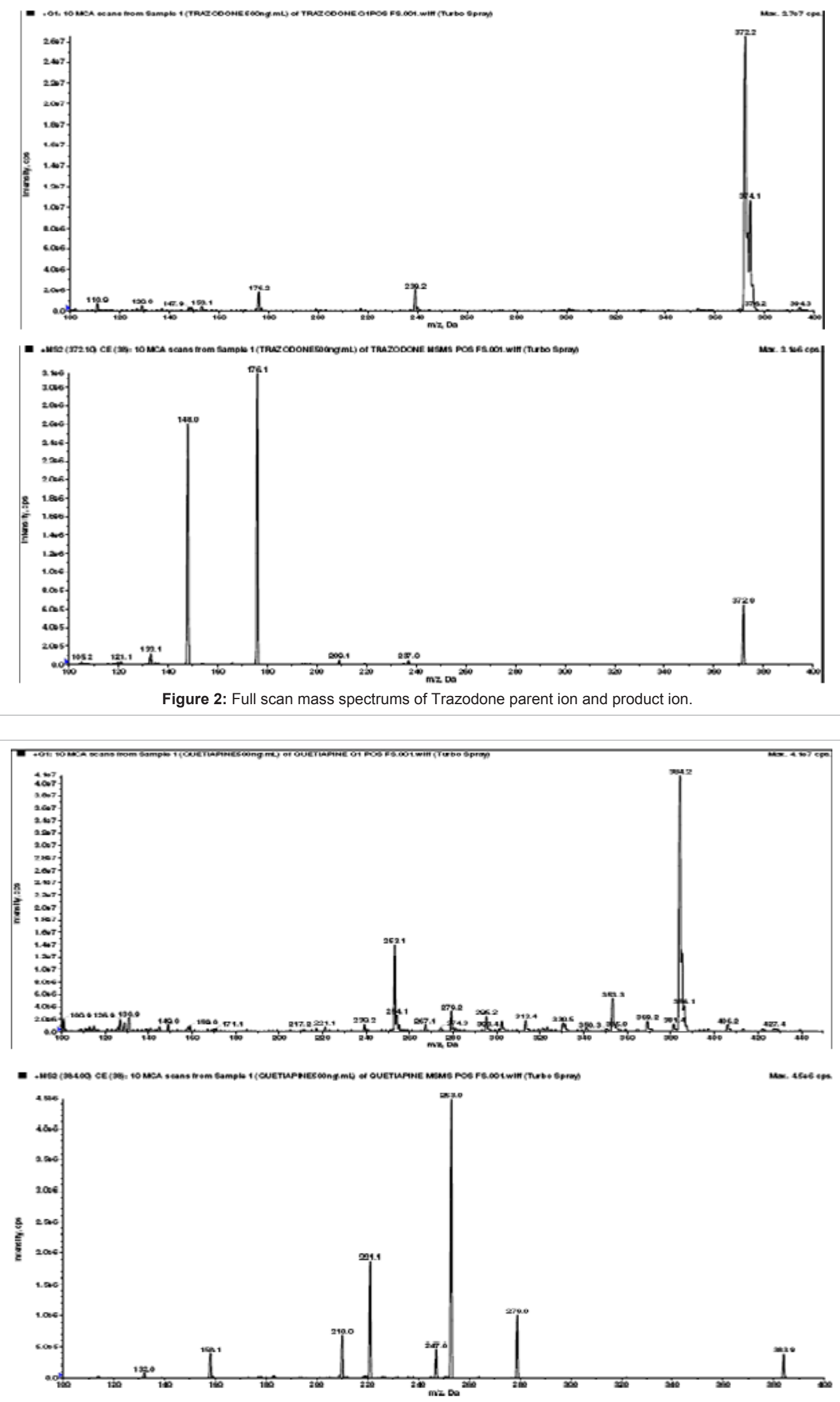

Figure 3: Full scan mass spectrums of Quetiapine parent ion and product ion. 


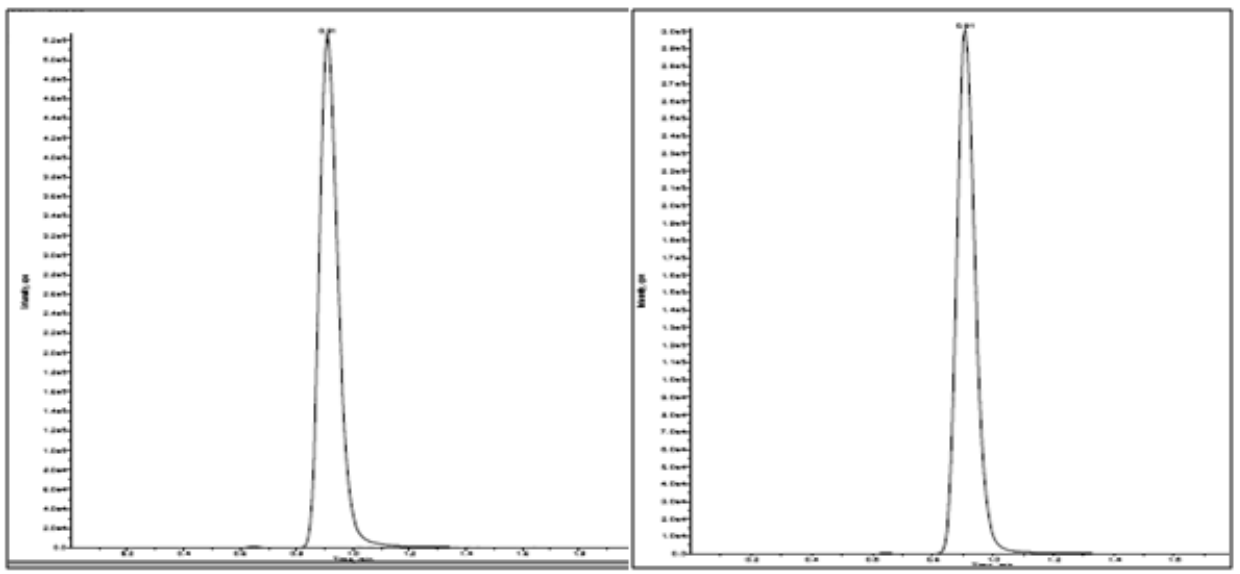

Figure 4: Retention time of Trazodone and Quetiapine.

\begin{tabular}{|c|c|c|c|c|c|c|c|c|c|c|c|c|}
\hline \multirow{2}{*}{ Matrix ID } & \multicolumn{2}{|c|}{ HPM/130/12 } & \multicolumn{2}{|c|}{ HPM/131/12 } & \multicolumn{2}{|c|}{ HPM/133/12 } & \multicolumn{2}{|c|}{ HPM/134/12 } & \multicolumn{2}{|c|}{ HPM/164/12 } & \multicolumn{2}{|c|}{ HPM/165/12 } \\
\hline & HQC & LQC & HQC & LQC & HQC & LQC & HQC & LQC & HQC & LQC & HQC & LQC \\
\hline & 614429 & 11790 & 621408 & 12122 & 619934 & 11708 & 616694 & 11386 & 605133 & 11253 & 583671 & 11043 \\
\hline & 623405 & 11773 & 605263 & 11195 & 604992 & 10925 & 582814 & 11269 & 618123 & 11527 & 590071 & 10717 \\
\hline & 608829 & 11491 & 615390 & 11573 & 603769 & 11461 & 621443 & 11642 & 594887 & 10677 & 603499 & 10866 \\
\hline N & 3 & 3 & 3 & 3 & 3 & 3 & 3 & 3 & 3 & 3 & 3 & 3 \\
\hline Average & 615554.3 & 11684.7 & 614020.3 & 11630 & 609565 & 11364.7 & 606983.7 & 11432.3 & 606047.7 & 11152.3 & 592413.7 & 10875.3 \\
\hline Standard Deviation & 7352.87 & 167.94 & 8159.18 & 466.12 & 9000.61 & 400.29 & 21065.8 & 190.77 & 11644.97 & 433.85 & 10119.46 & 163.2 \\
\hline CV (\%) & 1.2 & 1.4 & 1.3 & 4.0 & 1.5 & 3.5 & 3.5 & 1.7 & 1.9 & 3.9 & 1.7 & 1.5 \\
\hline
\end{tabular}

Table 2a: Results for matrix effect of Aprepitant.

\begin{tabular}{|c|c|c|c|c|c|c|c|c|c|c|c|c|}
\hline \multirow{2}{*}{ Matrix ID } & \multicolumn{2}{|c|}{ HPM/130/12 } & \multicolumn{2}{|c|}{ HPM/131/12 } & \multicolumn{2}{|c|}{ HPM/133/12 } & \multicolumn{2}{|c|}{ HPM/134/12 } & \multicolumn{2}{|c|}{ HPM/164/12 } & \multicolumn{2}{|c|}{ HPM/165/12 } \\
\hline & HQC & LQC & HQC & LQC & HQC & LQC & HQC & LQC & HQC & LQC & HQC & LQC \\
\hline & 157796 & 142794 & 154361 & 143363 & 157647 & 144131 & 156453 & 142050 & 150725 & 145502 & 155087 & 134696 \\
\hline & 154518 & 141267 & 151610 & 138063 & 157484 & 136738 & 153487 & 137155 & 151886 & 138790 & 149717 & 132549 \\
\hline & 154836 & 138796 & 157496 & 138351 & 155391 & 140020 & 155092 & 140002 & 153526 & 129473 & 152937 & 130175 \\
\hline $\mathrm{N}$ & 3 & 3 & 3 & 3 & 3 & 3 & 3 & 3 & 3 & 3 & 3 & 3 \\
\hline Average & 155716.7 & 140952.3 & 154489 & 139925.7 & 156840.7 & 140296.3 & 155010.7 & 139735.7 & 152045.7 & 137921.7 & 152580.3 & 132473.3 \\
\hline Standard Deviation & 1807.76 & 2017.49 & 2945.09 & 2980.3 & 1258.09 & 3704.24 & 1484.67 & 2458.34 & 1407.31 & 8049.7 & 2702.71 & 2261.45 \\
\hline CV (\%) & 1.2 & 1.4 & 1.9 & 2.1 & 0.8 & 2.6 & 1 & 1.8 & 0.9 & 5.8 & 1.8 & 1.7 \\
\hline
\end{tabular}

Table 2b: Results for matrix effect of Quetiapine.

\begin{tabular}{|c|c|c|c|c|c|c|c|}
\hline \multirow{2}{*}{ PLASMA ID } & \multicolumn{3}{|c|}{ Aprepitant } & \multicolumn{3}{|c|}{ Quetiapine } & \multirow{2}{*}{ IS Normalized Factor } \\
\hline & EXT & AQS & MF & EXT & AQS & MF & \\
\hline HPM/130/12 & 615554.3 & 581308 & 1.06 & 155716.7 & 146851 & 1.06 & 1.01 \\
\hline HPM/131/12 & 614020.3 & 587921 & 1.06 & 154489 & 148046 & 1.05 & 1.01 \\
\hline HPM/133/12 & 609565.0 & 583943 & 1.05 & 156840.7 & 147853 & 1.07 & 1.00 \\
\hline HPM/134/12 & 606983.7 & 578207 & 1.05 & 155010.7 & 148541 & 1.05 & 1.00 \\
\hline HPM/164/12 & 606047.7 & 580871 & 1.04 & 152045.7 & 145224 & 1.03 & 0.99 \\
\hline HPM/165/12 & 592413.7 & 570523 & 1.02 & 152580.3 & 146949 & 1.04 & 0.97 \\
\hline Average & 607430.78 & 580462.17 & 1.047 & 154447.18 & 147244 & 1.05 & 0.997 \\
\hline Standard deviation & 8265.515 & 5873.769 & 0.0151 & 1839.145 & 1184.75 & 0.0141 & 0.0151 \\
\hline$\% \mathrm{CV}$ & 1.4 & 1.0 & 1.4 & 1.2 & 0.8 & 1.3 & 1.5 \\
\hline
\end{tabular}

Table 2c: Results for IS Normalized factor at HQC level. 
Citation: Ravi Prakash PVDLS, Sumadhuri B, Srikanth M (2013) Determination of Aprepitant in Human Plasma by Using LC-MS/MS with Electrospray Ionization. J Bioequiv Availab 5: 110-116. doi:10.4172/jbb.1000143

\section{Linearity and Lower Limits of Quantification (LLOQ)}

Calibration curves were prepared by assaying plasma samples at eight concentrations of APT ranging $10.004-5001.952 \mathrm{ng} / \mathrm{ml}$ with correlation coefficient ( $r$ ) of 0.9991 (Figure 5). The linearity of each calibration curve was determined by plotting the peak area ratio(y) of APT to QTP versus the nominal concentration (x) of ATP. The calibration curves were constructed by weighed $\left(1 / \mathrm{x}^{2}\right)$ least square linear regression. The limit of detection was defined $(3.3 \mathrm{ng} / \mathrm{ml})$, as analyte responses are at least five times the response compared to blank responses. The lowest standard on the calibration curve $10.004 \mathrm{ng} /$ $\mathrm{ml}$ was defined as limit of quantification since the analyte peak was identifiable, discrete and reproducible with a precision of less than or equal to $20 \%$ and accuracy of $80-120 \%$ (Figure 6).

\section{Precision and accuracy}

The method precision and accuracy were evaluated by using replicate analysis of QC's at four concentrations of LLOQQC, LQC, MQC and HQC. Intra-day evaluation was done on the same day, whereas interday was done on consecutive days. Inter day batch accuracy ranged from $90.6 \%$ to $106.3 \%$. Inter day batch precision ranged from $2.4 \%$ to $10.8 \%$. Intraday batch accuracy ranged from $91.5 \%$ to $103.7 \%$. Intraday batch precision ranged from $2.0 \%$ to $7.9 \%$. The mean concentration, standard deviation (SD), coefficient of variation (\%CV) was evaluated and their results were tabulated in tables $3 \mathrm{a}$ and $3 \mathrm{~b}$.

\section{Extraction recovery}

Recovery analysis was repeated for six replicates at three concentrations (LQC, MQC and HQC). The extraction recovery of APT from spiked samples were determined by comparing the peak areas of analytes or internal standard in extracted samples to the corresponding peak areas of analytes or internal standard in post extracted spiked samples (extracted blank samples followed by spiking analyte and internal standard at a concentration level equivalent to $100 \%$ recovery). The results were represented in table 4 .

\section{Re-injection reproducibility}

The Re injection Reproducibility evaluation is done by comparing the results of re-injected set of samples with that of the original set and results were represented in table 5 .

\section{Stability studies}

Stability studies were carried out for stock solutions, stock dilutions and spiking solutions by comparing fresh stock and stability stock. Six

\begin{tabular}{|c|c|c|c|c|c|c|c|}
\hline \multirow{2}{*}{ PLASMA ID } & \multicolumn{3}{|c|}{ Aprepitant } & \multicolumn{3}{|c|}{ Quetiapine } & \multirow{2}{*}{$\begin{array}{l}\text { IS Normalized } \\
\text { Factor }\end{array}$} \\
\hline & EXT & AQS & MF & EXT & AQS & MF & \\
\hline HPM/130/12 & 615554.3 & 581308 & 1.06 & 155716.7 & 146851 & 1.06 & 1.01 \\
\hline HPM/131/12 & 614020.3 & 587921 & 1.06 & 154489 & 148046 & 1.05 & 1.01 \\
\hline HPM/133/12 & 609565.0 & 583943 & 1.05 & 156840.7 & 147853 & 1.07 & 1.00 \\
\hline HPM/134/12 & 606983.7 & 578207 & 1.05 & 155010.7 & 148541 & 1.05 & 1.00 \\
\hline HPM/164/12 & 606047.7 & 580871 & 1.04 & 152045.7 & 145224 & 1.03 & 0.99 \\
\hline HPM/165/12 & 592413.7 & 570523 & 1.02 & 152580.3 & 146949 & 1.04 & 0.97 \\
\hline Average & 607430.78 & 580462.17 & 1.047 & 154447.18 & 147244 & 1.05 & 0.997 \\
\hline Standard deviation & 8265.515 & 5873.769 & 0.0151 & 1839.145 & 1184.75 & 0.0141 & 0.0151 \\
\hline$\% \mathrm{CV}$ & 1.4 & 1 & 1.4 & 1.2 & 0.8 & 1.3 & 1.5 \\
\hline
\end{tabular}

Table 2d: Results for IS Normalized factor at LQC level.

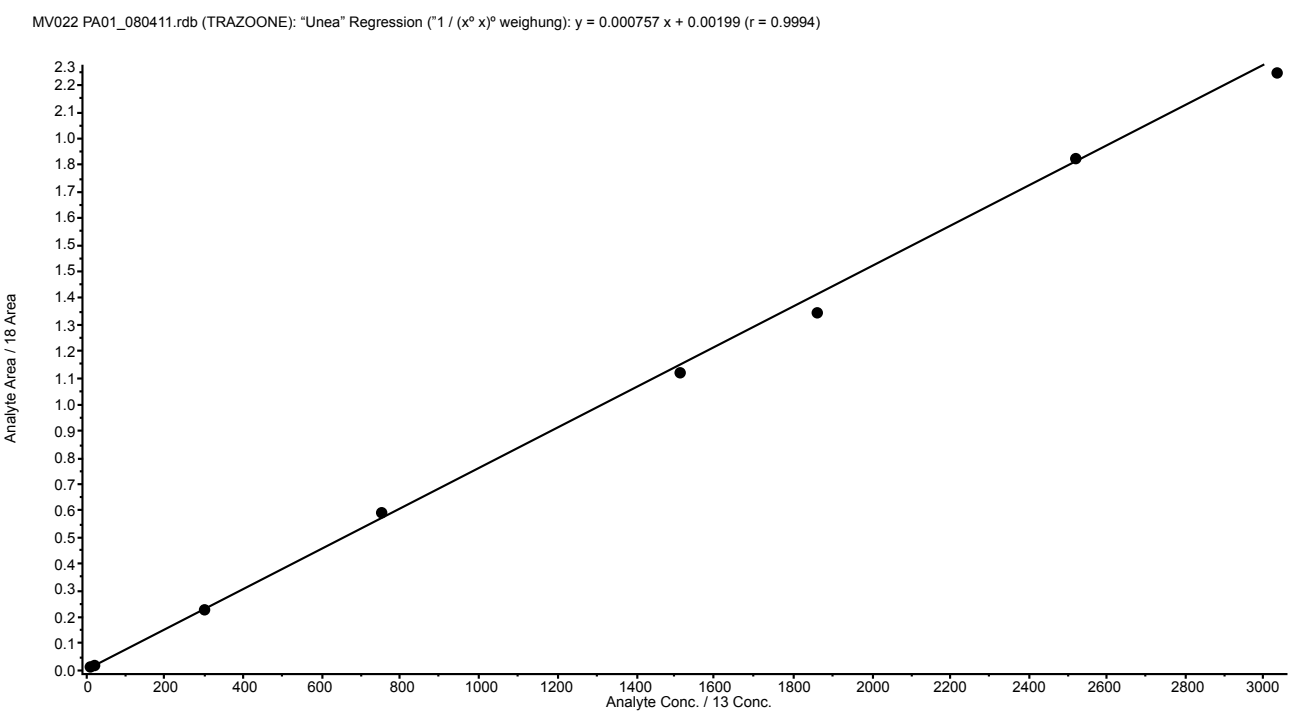

Figure 5: Calibration curve of Trazodone. 


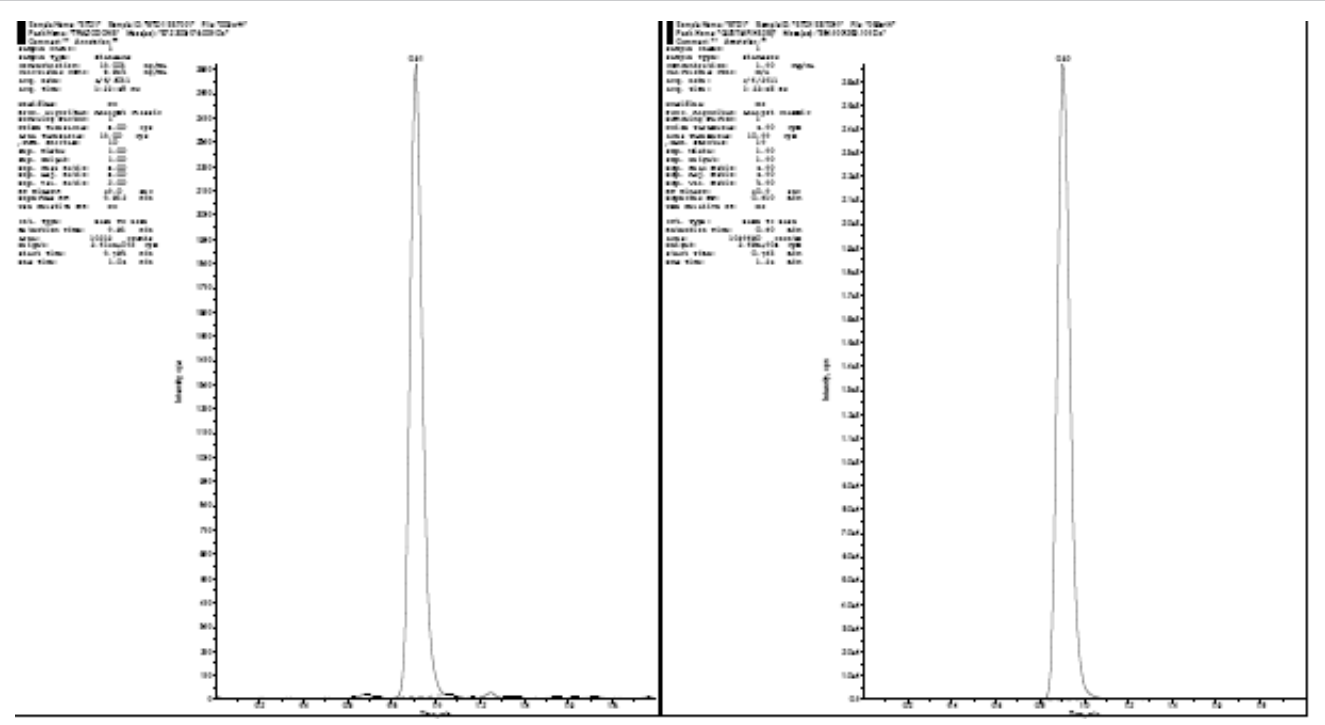

Figure 6: STD 1 of Trazodone and IS.

replicates of each Low quality control (LQC) and high quality control (HQC) samples were processed, analyzed and quantified against freshly prepared calibration curve. The precision and accuracy for the stability samples must be within $\leq 15$ and $\pm 15 \%$ of their respective nominal concentrations. Stability in biological matrix was carried for the following and the results were represented in table 6.

Freeze-thaw stability was obtained by taking the samples from the deep freezer at $-70^{\circ} \mathrm{C} \pm 15^{\circ} \mathrm{C}$ over five freeze-thaw cycles. The bench top stability was evaluated by keeping replicates of the LQC and HQC samples were withdrawn from deep freezer, kept at room temperature

\begin{tabular}{|c|c|c|c|c|}
\hline Batch & $\begin{array}{c}\text { Concentration } \\
\text { in ng/ml }\end{array}$ & $\begin{array}{c}\text { Mean Detected } \\
\text { Concentration, } \mathbf{\pm} \\
\text { SD (ng/ml) }\end{array}$ & $\begin{array}{c}\text { Mean } \\
\text { Accurracy (\%) }\end{array}$ & \%CV \\
\hline \multirow{3}{*}{ Intraday P\&A } & 3605.580 & $3586.306 \pm 13.54$ & 99.5 & 0.4 \\
\cline { 2 - 5 } & 2098.450 & $2084.240 \pm 7.88$ & 99.3 & 0.4 \\
\cline { 2 - 5 } & 25.181 & $24.276 \pm 1.22$ & 96.4 & 6.3 \\
\cline { 2 - 5 } & 10.576 & $9.187 \pm 0.08$ & 86.9 & 8.2 \\
\hline \multirow{3}{*}{ Interday P\&A } & 3605.580 & $3592.114 \pm 9.91$ & 99.6 & 0.3 \\
\cline { 2 - 5 } & 2098.450 & $2082.542 \pm 4.55$ & 99.2 & 0.2 \\
\hline & 25.181 & $22.651 \pm 1.18$ & 90.0 & 5.2 \\
\cline { 2 - 5 } & 10.576 & $9.137 \pm 0.32$ & 86.4 & 3.6 \\
\hline
\end{tabular}

Table 3a: Intra- and Inter- day Precision and Accuracy of Aprepitant sipcked in human plasma.

\begin{tabular}{|c|c|c|c|c|}
\hline PARAMETERS & HQC & MQC & LQC & LLOQ QC \\
\hline Nominal Conc. & 3605.58 & 2098.45 & 25.181 & 10.576 \\
\hline Mean & 3589.69 & 2083.77 & 23.542 & 9.166 \\
\hline SD ( \pm ) & 18.1303 & 8.6949 & 1.1647 & 0.9706 \\
\hline CV (\%) & 0.5 & 0.4 & 4.9 & 10.6 \\
\hline Accuracy & 99.6 & 99.3 & 93.5 & 86.7 \\
\hline
\end{tabular}

Table 3b: Precision and Accuracy studies of APT samples ( $\mathrm{ng} / \mathrm{ml})$. LLOQQC Lower limit of quantification Quality control samples, LQC - Lower Quality Control, MQC - Medium Quality Control, HQC - Higher Quality Control, SD - Standard Deviation and CV - Coefficient of variance.

\begin{tabular}{|c|c|c|c|c|}
\hline Drug & Nominal conc. & \% Recovery & Standard deviation & $\%$ CV \\
\hline Aprepitant & & & & \\
\hline HQC & $3605.580 \mathrm{ng} / \mathrm{ml}$ & 71.9 & 4.661 & 6.5 \\
\hline MQC & $2098.448 \mathrm{ng} / \mathrm{ml}$ & 68.0 & 2.585 & 3.8 \\
\hline LQC & $25.181 \mathrm{ng} / \mathrm{ml}$ & 63.8 & 2.718 & 4.3 \\
\hline Quetiapine & $400 \mathrm{ng} / \mathrm{ml}$ & 77.7 & 4.333 & 5.6 \\
\hline
\end{tabular}

Table 4: Extraction recovery data of analyte and internal standard.

\begin{tabular}{|c|c|c|}
\hline \multicolumn{3}{|c|}{ Observed Concentration(ng/ml) } \\
\hline Parameter & HQC & LQC \\
\hline Average Conc. & 3595.66 & 23.952 \\
\hline Standard Deviation & 5.4635 & 0.7881 \\
\hline CV (Precision \%) & 0.2 & 3.3 \\
\hline Nominal Conc. & 3605.58 & 25.181 \\
\hline Accuracy (\%) & 99.7 & 95.1 \\
\hline
\end{tabular}

Table 5: Results for reinjection reproducibility.

\begin{tabular}{|c|c|c|c|}
\hline \multirow{2}{*}{ STABILITIES } & \multirow{2}{*}{ TIME } & \multicolumn{2}{|c|}{ \% STABILITY } \\
\hline Freeze-thaw & & HQC & LQC \\
\hline Bench top & 5 cycles & 96.3 & 98.9 \\
\hline Wet extract at refrigerator & $17 \mathrm{~h}$ & 92.3 & 94.3 \\
\hline Wet extract at bench top & $41 \mathrm{~h}$ & 95.9 & 96.1 \\
\hline Dry extract & $17 \mathrm{~h}$ & 95.3 & 100.5 \\
\hline Auto sampler & $41 \mathrm{~h}$ & 94.9 & 92.8 \\
\hline Interim & $41 \mathrm{~h}$ & 101.4 & 96.9 \\
\hline & 03 days & 104.9 & 101.5 \\
\hline
\end{tabular}

Table 6: Results for Stability Studies.

approximately for 17 hours (hrs). Wet extract stability of the samples evaluated at room temperature and refrigerator approximately for 17 hrs and 41 hrs respectively. Dry extract stability of the samples evaluated at refrigerator conditions for $41 \mathrm{hrs}$. Auto injector stability was evaluated for $41 \mathrm{hrs}$. Samples were initially stored in $-25^{\circ} \mathrm{C}$ and later retrieved after 03 days. The samples were then processed and analyzed. 


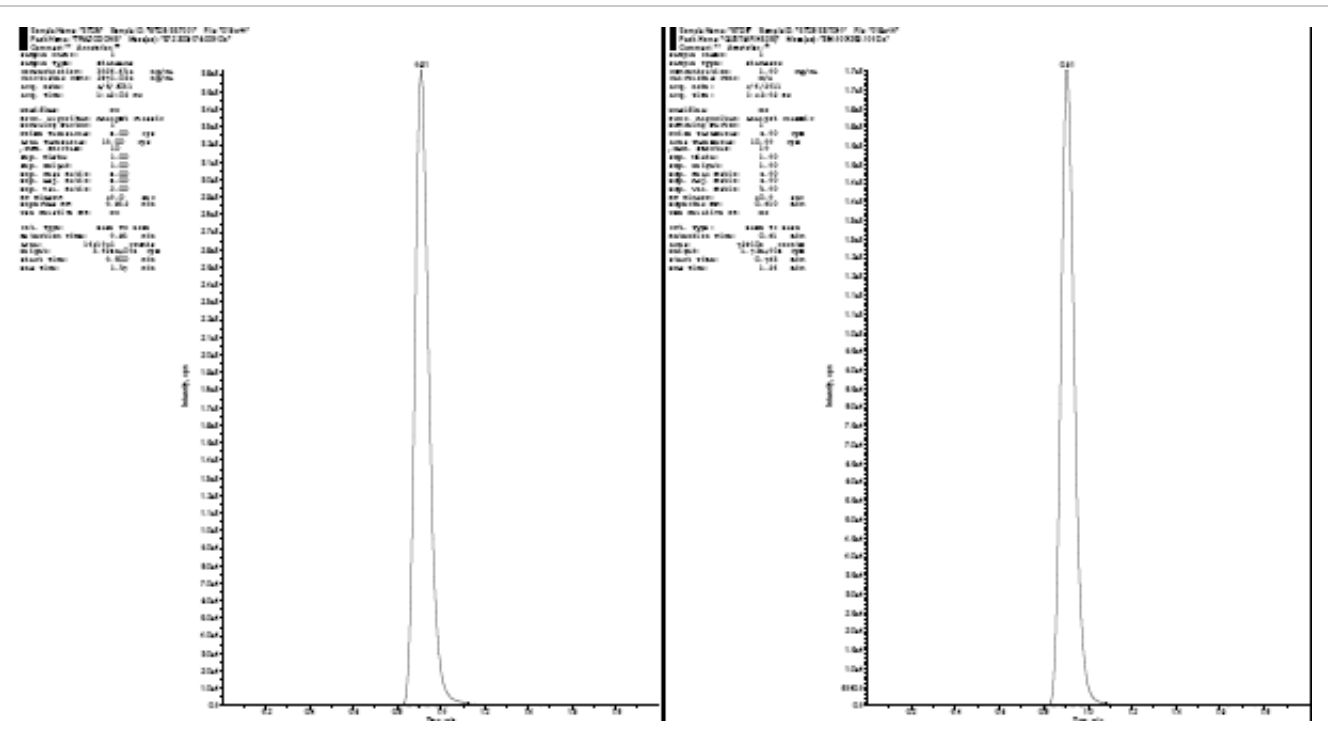

Figure 7: STD 8 of Trazodone and IS.

\section{Conclusion}

A highly selective and rapid LCMS/MS method employing liquidliquid extraction for the determination of APT in human plasma has been developed and validated with a Lower limit of Quantification of $10.004 \mathrm{ng} / \mathrm{ml}$. The validation data also demonstrates good precision, accuracy and high extraction efficiency. The validated method allows quantification of APT in the linear range of 10.004-5001.952 ng/ml. In conclusion, this paper describes a very simple and sensitive LCMS/ MS method for the quantization of APT suitable to monitor plasma concentrations during clinical pharmacokinetic and bioequivalence studies in humans.

\section{Acknowledgement}

The author would like to thank Actimus Biosciences Pvt.Ltd., India for the technical support. The author is indebted to Professors Dr. I.Mrityunjaya Rao and Dr. N.Someswara Rao for the fruitful discussion. The author gratefully acknowledges the competent technical assistance of M.Srinivasa Reddy and S.Vijay Bhaskar Reddy.

\section{References}

1. Bergstrom M, Hargreaves RJ, Burns HD, Goldberg MR, Sciberras D, et al (2004) Human positron emission tomography studies of brain neurokinin 1 receptor occupancy by aprepitant. Biol Psychiatry 55: 1007-1012.

2. Gralla RJ, de Wit R, Herrstedt J, Carides AD, lanus J, et al. (2005) Antiemetic efficacy of the neurokinin-1 antagonist, aprepitant, plus a 5HT3 antagonist and a corticosteroid in patients receiving anthracyclines or cyclophosphamide in addition to high-dose cisplatin: analysis of combined data from two Phase III randomized clinical trials. Cancer 104: 864-868.

3. Sreekanth Nama, Bahlul Z Awen, Babu Rao Chandu, Mukkanti Khagga (2011) A Validated Stability-Indicating RP-HPLC Method for the Determination of Aprepitant in Bulk and Pharmaceutical Dosage Forms. Recent Research in Science \& Technology 3: 16-24.

4. Lai JP, Ho WZ, Zhan GX, Yi Y, Collman RG, et al. (2001) Substance P antagonist (CP-96,345) inhibits HIV-1 replication in human mononuclear phagocytes. Proc Natl Acad Sci U S A 98: 3970-3975.

5. Barrett JS (2007) Facilitating compound progression of antiretroviral agents via modeling and simulation. J Neuroimmune Pharmacol 2: 58-71.

6. Ashok S, Raghunadhababu CV, Satish Varma M, Balaswamy G (2012) Separation and Quantification of Process Related Impurities and Diastereomers in Aprepitant Bulk Drug Substance. Journal of Liquid Chromatography \& Related Technologies 35: 677-687.

7. Helmy R, Zhou GX, Chen YW, Crocker L, Wang T, et al. (2003) Characterization and quantitation of aprepitant drug substance polymorphs by attenuated total reflectance fourier transform infrared spectroscopy. Anal Chem 75: 605-611.

8. Dupuis LL, Lingertat-Walsh K, Walker SE (2009) Stability of an extemporaneous oral liquid aprepitant formulation. Support Care Cancer 17: 701-706.

9. Kiran Kumar V, Appala Raju N, Begum SH, Seshagiri Rao JVLN, Satyanarayana T (2009) The Estimation of Aprepitant in Capsules Dosage forms by RP-HPLC. Research J Pharm and Tech 2: 412-414.

10. Skrdla PJ, Abrahim A, Wu Y (2006) An HPLC chromatographic reactor approach for investigating the hydrolytic stability of a pharmaceutical compound. J Pharm Biomed Anal 41: 883-890.

11. Huskey SE, Dean BJ, Doss GA, Wang Z, Hop CE, et al. (2004) The metabolic disposition of aprepitant, a substance $P$ receptor antagonist, in rats and dogs. Drug Metab Dispos 32: 246-258.

12. Di Wu, Dustin JP, Xianguo Z, Steven D, Jeffrey SB (2009) A Sensitive and Rapid Liquid Chromatography-Tandem Mass Spectrometry Method for the Quantification of the Novel Neurokinin-1R Antagonist Aprepitant in Rhesus Macaque Plasma and Cerebral Spinal Fluid and Human Plasma with Application in Translational Neuro AIDS Research. J Pharm Biomed Anal 49: 739-745.

13. Chavez-Eng CM, Constanzer ML, Matuszewski BK (2004) Simultaneous determination of Aprepitant and two metabolites in human plasma by highperformance liquid chromatography with tandem mass spectrometric detection. J Pharm Biomed Anal 35: 1213-1229.

14. Constanzer ML, Chavez-Eng CM, Dru J, Kline WF, Matuszewski BK (2004) Determination of a novel substance $\mathrm{P}$ inhibitor in human plasma by highperformance liquid chromatography with atmospheric pressure chemical ionization mass spectrometric detection using single and triple quadrupole detectors. J Chromatogr B Analyt Technol Biomed Life Sci 807: 243-250.

15. US Department of Health and Human Services, Food and Drug Administration (2001) Guidance for Industry Bioanalytical Method Validation. 